\title{
Propuesta de actividades para la enseñanza de las ecuaciones diferenciales, con variables separables mediante el apoyo de software libre "geogebra"
}

Luis Alberto Jaimes Contreras ${ }^{1}$, Rafael Felipe Chaves Escobar ${ }^{2}$

\section{Resumen}

La nueva pedagogía viene realizando grandes aportes con el propósito de mejorar los procesos de enseñanza aprendizaje en la educación, sin embargo según Morales Lopez y Salas Huertas (2010) en el estudio de las ecuaciones diferenciales (ED) actualmente "predomina el enfoque algebraico como reflejo de la primera forma que se tuvo de resolver estos problemas" y que algunos docentes emplean como estrategia didáctica.

Palabras claves: Enseñanza, Ecuaciones Diferenciales, Variables separables, Geogebra.

\section{Summary}

The new pedagogy has been making great contributions for the purpose of improving teaching and learning processes in education, however according Huertas Morales Lopez and Salas (2010) in the study of differential equations (ED) now "predominantly reflecting algebraic approach of the first form that had to solve these problems "and that some teachers use as a teaching strategy.

Keywords: Teaching, Differential Equations, Separable equations, Geogebra.

\section{Introducción}

U no de los factores que ha motivado a los investigadores a abordar el campo de los procesos de enseñanza aprendizaje de las ED es el cuestionamiento ipor qué la enseñanza de las ED está basada en su mayor parte en técnicas analíticas de solución? (Dullius, 2009, p. 37). Cuestionamiento por el cual se han realizado in- vestigaciones con el objetivo de proponer un método de enseñanza que permita al estudiante conocer el significado de solución de una ecuación diferencial, mediante la integración de los enfoques algebraico, numérico y geométrico (Nápoles et al. 2004, p. 48). En las investigaciones realizadas por Dullius (2009) y Nápoles et al. (2004), se resalta el trabajo con recursos computacionales, los cuales han permitido interpretar de una forma más clara las ED y sus soluciones partiendo de la

\footnotetext{
${ }^{1}$ Docente Universidad Distrital Francisco José de Caldas. E-mail: lajaimesc@udistrital.edu.co

${ }^{2}$ Docente Universidad Distrital Francisco José de Caldas. E-mail: rafach_25@hotmail.com
} 
integración de los tres enfoques mencionados por Nápoles et al. (2004).

Ahora bien, justificada la necesidad de incluir los recursos tecnológicos en los procesos de enseñanza aprendizaje de las ED, sabemos que desafortunadamente nuestro país no invierte en educación una cifra significativa. Por tal motivo es posible que encontremos universidades públicas que no tengan la capacidad de adquirir la licencia de funcionamiento de determinado software el cual sea aplicable para la enseñanza de las ED, lo cual dificulta integrar los enfoques algebraico y geométrico con la ayuda de recursos tecnológicos.

\section{Propuesta}

Es por esto que esta investigación pretende plantear una propuesta de actividades que integren los enfoques algebraico y geométrico, con el apoyo de software libre, la cual podría ser implementada en cualquier universidad pública, sin generar costos significativos en su presupuesto.

Para Nápoles Valdés, González Thomas, Brundo, Genes, y Basabilbaso (2004) en la enseñanza de las ED algunos conceptos relacionados con límite, derivación e integración son evadidos o disfrazados con fórmulas o algoritmos, lo cual impide la comprensión precisa del concepto llevando al estudiante, y en ocasiones a los docentes, a concebir la fórmula como el concepto en sí mismo.

En libros de ED (Zill D., Cullen M., (2008); Carmona J. (2011); Apostol T. M. (1988)), entre otros, generalmente el primer método analítico que se trabaja para resolverlas es el de variables separables debido a que es considerado como uno de los métodos más sencillos de desarrollar y que se aplica a la solución de modelos lineales de primer orden, como crecimiento y decaimiento, fechado por carbono, ley de newton sobre enfriamiento y calentamiento, mezclas, etc.

En una encuesta aplicada a estudiantes del programa de construcciones civiles de la Universidad Distrital Francisco José de Caldas, los estudiantes debían elegir de los siguientes modelos: "Dinámicas de población, decaimiento radioactivo, ley de enfriamiento y calentamiento de Newton, difusión de una enfermedad y mezclas" dos de los cuales a su consideración representan mayor aplicabilidad en su formación como ingenieros civiles. Los modelos con mayor porcentaje de elección fueron: Mezclas y ley de enfriamiento y calentamiento de Newton, razón por la cual se elige el modelo de mezclas para trabajar en la propuesta.

Por los motivos expresados, es necesario diseñar e implementar una propuesta de actividades para la enseñanza de las ED con variables separables que complemente el método analítico con el enfoque geométrico mediante la ayuda de software libre "Geogebra" para de esta forma mejorar las conexiones entre las ED, sus soluciones y representaciones.

\section{Bibliografía}

Apostol T. M. (1988). Calculus, Vol 2. Segunda Edición, Editorial Reverté.

Carmona J. (2011) Ecuaciones diferenciales Quinta Edición, Editorial Pearson.

Dullius, M. M. (2009). Enseñanza y aprendizaje en ED con abordaje gráfico, numérico y analítico. Tesis Doctoral. Burgos, España.

Morales López, Y., \& Salas Huertas, O. (2010). Incorporación de la tecnología para la enseñanza y aprendizaje de las ED ordinarias. Cuadernos de Investigación y Formación en Educación Matemática, 6, 155-172.

Nápoles Valdés, J. E., González Thomas, A., Brundo, J. M., Genes, F., \& Basabilbaso, F. (2004). El enfoque histórico problémico en la enseñanza de la matemática para ciencias técnicas: el caso de las ecuaciones diferenciales ordinarias. Acta Scientiae, $6,41-59$

Zill D., Cullen M. (2008). Matemáticas avanzadas para ingenieria, vol 1: Ecuaciones diferenciales Tercera Edición, Editorial McGraw-Hill. 